\title{
Hemophagocytic lymphohistiocytosis and congenital factor VII deficiency: a case report
}

\author{
Xiong Wang ${ }^{1 \dagger}$, Ning Tang ${ }^{1 \dagger}$, Wei Chang ${ }^{2^{*}}$, Yanjun Lu' ${ }^{1^{*}}$ and Dengju $\mathrm{Li}^{3^{*}}$
}

\begin{abstract}
Background: Hemophagocytic lymfohistiocytosis $(H L H)$ is a rare, life-threatening hyperinflammation, characterized by immune system over-activation resulting in hemophagocytosis. HLH could appear as a primary disease caused by mutations of immune-regulatory genes, or develop as a result of viral or bacterial infections, or malignancy. Congenital factor VII (FVII) deficiency is a rare autosomal recessive disorder characterized by prolonged prothrombin time (PT) and low FVII, which may increase bleeding risk.

Case presentation: A 50-year-old woman was admitted for a fever persisted for 20 days, presenting with cytopenia, high hyperferritinemia, low activity of NK cells. Bone marrow aspiration showed hemophagocytosis. CT scanning found pulmonary infection. EBV and CMV were not detected. Genetic scanning did not find pathogenic mutation of a HLH NGS panel including 26 genes. This patient was treated as recommended by the HLH 2004 Guidelines. Coagulation tests identified FVII deficiency. Genetic analysis of F7 gene in the patient and her family members identified recurrent compound heterozygous F7 c.64 + 5G > A and c.1224 T> G (p.His408Gln) mutations in this patient and her brother who showed postoperative hemorrhage after surgical resection of renal cell carcinoma. Heterozygotes in this family were asymptomatic.
\end{abstract}

Conclusions: To our knowledge, this is the first report of HLH in combination with congenital FVII deficiency in Chinese population.

Keywords: Hemophagocytic lymfohistiocytosis, Infection, Hemophagocytosis, Factor VII deficiency

\section{Background}

Hemophagocytic lymphohistiocytosis (HLH) is a very rare life-threatening syndrome characterized by excessive immune activation and hyperinflammation [1]. HLH can be either familial or secondary to infection, immunosuppression, autoimmune disease, and malignancy [2]. Acquired HLH is an aggressive clinical entity which require early diagnosis and appropriate therapies. Management of HLH was indicated in the HLH-2004 guidelines, although it was heavily debated [3]. An especially

\footnotetext{
*Correspondence: cwei200408@163.com; junyanlu_2000@163.com; lidengju@163.com

${ }^{\dagger}$ Xiong Wang and Ning Tang contributed equally to this work. ${ }^{2}$ Department of Hematology, China Resource \& WISCO General Hospital, Wuhan University of Science and Technology, Wuhan 430081, China 'Department of Laboratory Medicine, Tongji Hospital, Tongji Medical College, Huazhong University of Science and Technology, Wuhan 430030, China ${ }^{3}$ Department of Hematology, Tongji Hospital, Tongji Medical College,

Huazhong University of Science and Technology, Wuhan 430030, China
}

high incidence of Epstein-Barr virus (EBV)-associated HLH (EBV-HLH) was found in Asia $[4,5]$.

Congenital factor VII (FVII) deficiency (OMIM: 227500) is a rare inheritable coagulation disorder with an estimated prevalence of 1:500000, and is inherited in autosomal recessive (AR) model. Clinical manifestations vary from asymptomatic to severe bleeding, and the clinical manifestations do not correlate well with plasma FVII levels, which lead to the patient management during surgery challenging [6]. Congenital FVII deficiency is characterized by prolonged prothrombin time (PT) and low FVII. 30\% was considered as the cutoff for clinical manifestations in patients with FVII deficiency [7].

We hereby report the first case of patient suffered from both HLH and congenital FVII deficiency.

(c) The Author(s). 2018 Open Access This article is distributed under the terms of the Creative Commons Attribution 4.0 International License (http://creativecommons.org/licenses/by/4.0/), which permits unrestricted use, distribution, and reproduction in any medium, provided you give appropriate credit to the original author(s) and the source, provide a link to the Creative Commons license, and indicate if changes were made. The Creative Commons Public Domain Dedication waiver (http://creativecommons.org/publicdomain/zero/1.0/) applies to the data made available in this article, unless otherwise stated. 


\section{Case presentation \\ $\mathrm{HLH}$}

The 50-year-old woman was admitted for a fever persisted for 20 days. Computed tomography (CT) scanning showed pulmonary infection. Cytopenia was observed in peripheral blood. White blood cells, red blood cells, and neutrophil graneulocytes were all decreased. Hemoglobin was only $74.0 \mathrm{~g} / \mathrm{L}$. Ferritin was increased to be $3602.5 \mathrm{~g} / \mathrm{L}$. Autoimmune antibody test found no abnormity. The available laboratory data were summarized in Table 1.

Table 1 Laboratory test results

\begin{tabular}{|c|c|c|c|}
\hline Test & Result & Reference & Unit \\
\hline$\overline{\text { WBC }}$ & $1.24(\downarrow)$ & $3.50-9.50$ & $10^{9} / \mathrm{L}$ \\
\hline GRA (\%) & 61.3 & $40.0-75.0$ & $\%$ \\
\hline GRA (\#) & $0.76(\downarrow)$ & $1.80-6.30$ & $10^{9} / \mathrm{L}$ \\
\hline LYN (\%) & 37.9 & $20.0-50.0$ & $\%$ \\
\hline LYN (\#) & $0.47(\downarrow)$ & $1.10-3.20$ & $10^{9} / \mathrm{L}$ \\
\hline MONO (\%) & $0.8(\downarrow)$ & $3.0-10.0$ & $\%$ \\
\hline MONO (\#) & $0.01(\downarrow)$ & $0.10-0.60$ & $10^{9} / \mathrm{L}$ \\
\hline EOS (\%) & $0.0(\downarrow)$ & $0.4-8.0$ & $\%$ \\
\hline EOS (\#) & $0.00(\downarrow)$ & $0.02-0.52$ & $10^{9} / \mathrm{L}$ \\
\hline BAS (\%) & $0.0(\downarrow)$ & $0-1.0$ & $\%$ \\
\hline BAS (\#) & $0.00(\downarrow)$ & $0.00-0.06$ & $10^{9} / \mathrm{L}$ \\
\hline $\mathrm{RBC}$ & $2.67(\downarrow)$ & $3.80-5.10$ & $10^{12} / \mathrm{L}$ \\
\hline$H B$ & $74.0(\downarrow)$ & $115.0-150.0$ & $g / L$ \\
\hline $\mathrm{HCT}$ & $22.0(\downarrow)$ & $35.0-45.0$ & $\%$ \\
\hline MCV & 82.4 & $82.0-100.0$ & $\mathrm{fL}$ \\
\hline $\mathrm{MCH}$ & 27.7 & $27.0-34.0$ & pg \\
\hline $\mathrm{MCHC}$ & 336 & $316-354$ & $g / L$ \\
\hline PLT & 146.0 & $125.0-350.0$ & $10^{9} / \mathrm{L}$ \\
\hline PDW & 10.3 & $9.0-17.0$ & $\mathrm{fL}$ \\
\hline MPV & 9.9 & $8.0-15.0$ & $\mathrm{fL}$ \\
\hline P-LCR & 23.3 & $13.0-43.0$ & $\%$ \\
\hline PCT & 0.14 & $0.10-0.25$ & $\%$ \\
\hline FER & $3602.5(\uparrow)$ & $15-150$ & $\mu g / L$ \\
\hline ALT & $53(\uparrow)$ & $\leq 33$ & $U / L$ \\
\hline AST & $60(\uparrow)$ & $\leq 32$ & $\mathrm{U} / \mathrm{L}$ \\
\hline LDH & $737(\uparrow)$ & $135-214$ & $U / L$ \\
\hline ALP & $126(\uparrow)$ & 35-105 & $U / L$ \\
\hline EBV & Negative & Negative & - \\
\hline CMV & Negative & Negative & - \\
\hline
\end{tabular}

WBC white blood cell, GRA neutrophil graneulocyte, LYN lymphocyte, MONO Monocyte, EOS eosinophil, BAS basophil, $R B C$ red blood cell, $H B$ hemoglobin, $H C T$ hematocrit, $M C V$ erythrocyte mean corpuscular volume, $M C H$ mean corpuscular hemoglobin, $M C H C$ mean red blood cell hemoglobin concentration, PLT platelet, PDW platelet distribution width, MPV mean platelet volume, $P$ - $L C R$ proportion of large platelet, $P C T$ plateletcrit, FER ferritin, $A L T$ alanine aminotransferase, $A S T$ aspartate aminotransferase, $L D H$ lactate dehydrogenase, $A L P$ alkaline phosphatase, EBV Epstein-Barr virus, CMV Cytomegalovirus
NK cells activity was detected according to IFN- $\gamma$ secretion by using whole blood as previously established in our laboratory [8]. Moreover, functional activity of NK cells was detected using K562 cells as target cells. Low activity of NK cells was found in two assays. In both assays, the activity of NK cells was only $30 \%$ of the low limit of healthy controls. Bone marrow aspiration confirmed hemophagocytosis (Fig. 1). Laboratory tests exclude EBV or Cytomegalovirus (CMV) infection, common cause of HLH. This patient was diagnosed and treated according to HLH-2004 guidelines $[9,10]$.

To explore the genetic cause of HLH in this patient, a targeted next generation sequencing (NGS) panel was applied, including LYST, CTPS1, PIK3CD, PRF1, SRGN, CD27, LAMP1, ARF6, GZMB, RAB27A, BLOC1S6, CORO1A, UNC13D, STXBP2, GNLY, STK4, PRKCD, AP3B1, ITK, STX11, CARD11, MCM4, MAGT1, SH2D1A, XIAP, and IL2RG genes. The mean depth was 315 folds. $98.44 \%$ of target region was covered by at least 20 folds. The NGS was performed on the Ion Torrent Personal Genome Machine as previously described [11]. However, NGS targeting HLH associated gene found no pathogenic variant.

\section{Congenital FVII deficiency}

Coagulation tests showed the FVII:C was decreased to be $4 \%$. The FVII:C of the patient's brother was $5 \%$, who suffered postoperative hemorrhage after surgical resection of renal cell carcinoma 3 years ago. Both the patient and her brother showed prolonged PT. Family tree was drawn (Fig. 2a). Genomic DNA was extracted from peripheral blood mononuclear cell (PBMC). Coding exons and adjacent splice junctions were amplified for the F7 gene. Sanger sequencing was performed bi-directionally on ABI 3500 Dx. NM_000131.4 was used as reference transcript of the $F 7$ gene. Genetic analysis of the $F 7$ gene in the patient and her family members identified

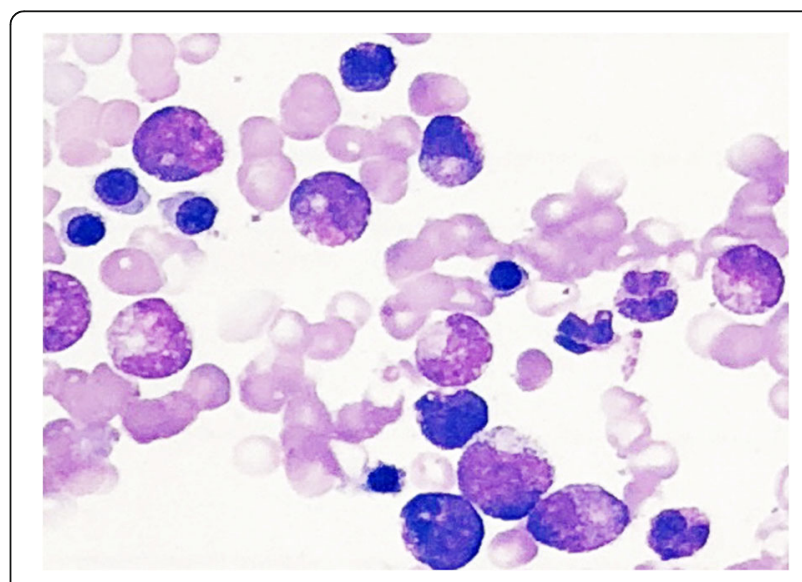

Fig. 1 Bone marrow aspiration. Mononuclear histiocyte with engulfed erythrocyte was observed. $\mathrm{G}=64.5 \%, \mathrm{E}=31.5 \%$, $\mathrm{G} / \mathrm{E}=2.05: 1$ 


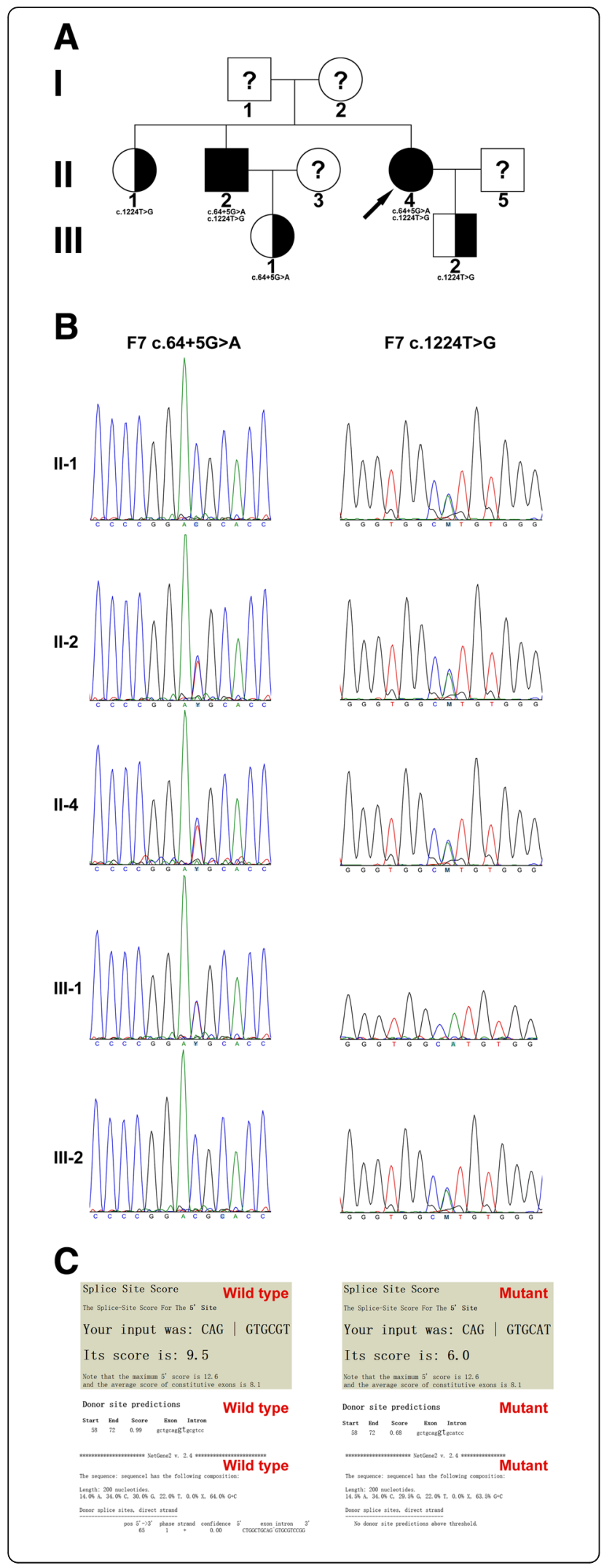

Fig. 2 Congenital factor VII (FVII) deficiency. a, The family tree of a Chinese family with $\mathrm{HLH}$ and congenital FVII deficiency. Square and circle denoted male or female respectively. Full-filled square and circle meant patients, and half-filled symbols represented heterozygous carrier. The arrow indicated the proband. A question mark meant that genetic analysis was unavailable. $\mathbf{b}$, Sanger sequencing of F7 c.64 + 5G > A and c.1224 T> G mutations. c, Splicing site prediction by Splice Site Score Calculation (http://rulai.cshl.edu/new_alt_exon_db2/HTML/ score.html), Splice Site Prediction by Neural Network (http://www. fruitfly.org/seq_tools/splice.html), and Netgene2 (http://www.cbs.dtu. $\mathrm{dk} /$ services/NetGene2/)

recurrent compound heterozygous $F 7$ c. $64+5 \mathrm{G}>\mathrm{A}$ and c.1224 $\mathrm{T}>\mathrm{G}$ (p.His408Gln) mutations in this patient and her brother. Heterozygotes were found in other family members who showed slightly decreased FVII:C (Fig. 2b, Table 2). Heterozygotes were asymptomatic.

\section{Discussion and conclusions}

HLH is a severe or fatal inflammatory condition caused by hereditary or acquired immunoregulatory abnormity. Inflammatory cytokine storm caused by the excessive activation and proliferation of macrophages and T-lymphocytes may contribute to HLH pathology $[12,13]$. Primary HLH is an autosomal or X-linked recessive immune disorders. Secondary HLH is often precipitated by infection, autoimmune disease, malignancy, or metabolic conditions, and its prognosis is poor. The initial clinical manifestations of HLH may vary widely and lead to misdiagnosis. For secondary HLH, 8 criteria were proposed (fever, splenomegaly, cytopenia, hypertryglyceridemia or hypofibrinogenemia, high ferritin, elevated soluble CD25, low NK cell activity, and hemophagocytosis in biopsy) and the presence of $5 / 8$ of these criteria confirmed the diagnosis [10]. Prompt start of therapy was essential and lifesaving. In this study, the patient received anti-infection therapy with Moxifloxacin Hydrochloride for 6 days, and then she was transferred to our department and treated according to HLH-2004 when her fever persisted for 20 days. CT scanning showed pulmonary infection. EBV was not detected, and malignancy could not be excluded.

FVII is involved in the 'initiation' phase via binding tissue factor exposed by cells after endothelial injury. The complex promotes the activation of factor $\mathrm{X}$ and IX, leading to the generation of thrombin [14]. Congenital FVII deficiency is an AR disorder, which is defined by

Table 2 Congenital FVII deficiency

\begin{tabular}{lllllll}
\hline No. & Age (year) & F7 c.64 + 5G > A & F7 c.1224 T > G & PT & APTT & FVII:C \\
\hline$\|-1$ & 63 & Wild type & Heterozygous & 14.2 & - & 67 \\
$\|-2$ & 61 & Heterozygous & Heterozygous & 28.4 & 38.9 & 5 \\
$\|-4$ & 50 & Heterozygous & Heterozygous & 30.3 & 34.6 & 4 \\
III-1 & 36 & Heterozygous & Wild type & 14.4 & 33.5 & 45 \\
$\| I-2$ & 28 & Wild type & Heterozygous & 14.5 & 37.1 & 51 \\
\hline
\end{tabular}


the complete absence or below $70 \%$ of normal of FVII [15]. Clinical manifestations of FVII deficiency were heterogeneous, varying from asymptomatic to fatal bleeding, which do not correlate well with FVII plasma levels. Laboratory test for FVII activity is the first-line method for FVII deficiency diagnosis.

In this family, compound heterozygous $F 7$ c. $64+5 \mathrm{G}>$ A and c.1224 T > G mutations were found in the patient and her brother. Homozygous F7 c.64 + 5G > A mutation has been previously reported [16]. Peyvandi $F$ et al., reported that this mutation might result in the preservation of some FVII coagulant activity and was associated with a mild bleeding history. Three kinds of splicing software were used to predict the effect of $F 7$ c.64+ $5 \mathrm{G}>\mathrm{A}$ mutation on $5^{\prime}$ splicing site (Fig. 2c). The $5^{\prime}$ splicing site of exon 1 was predicted to be greatly influenced by $F 7$ c. $64+5 \mathrm{G}>\mathrm{A}$ mutation. F7 c. $1224 \mathrm{~T}>\mathrm{G}$ mutation resulted in amino acid substitution of $\mathrm{His}^{408}$ to Gln. Katsumi A et al., reported that his mutation leads to impaired secretion of the molecule and FVII deficiency in vitro [17]. In this family, heterozygotes showed slightly decreased FVII:C, while the patient and her brother showed greatly decreased FVII:C level, both of whom carried compound heterozygous F7 c.64+5G $>\mathrm{A}$ and c.1224 $\mathrm{T}>\mathrm{G}$ mutations. These results were consistent with the AR inheritance model.

Bleeding and altered coagulation can occur in patients with $\mathrm{HLH}$, but, vice versa, coagulation defects are associated to more severe HLH $[18,19]$. The most frequently reported hemostasis abnormity is hypofibrinogenemia partially due to fibrinogen consumption by disseminated intravascular coagulation (DIC) [1]. DIC and thrombocytopenia were associated with adverse outcome in HLH patients [20]. FVII interacts with tissue factor and activates factor X (FX) binding to platelets, leading to thrombin formation. Thrombin plays a role in the activation of platelets, cleavage of fibrinogen to produce fibrin, and stabilization of clot by the actions of activated factor XIII [21]. Recombinant factor VIIa (rFVIIa) has been used successfully in HLH patients with severe hemorrhage [22, 23]. FVII deficiency may increase the bleeding risk of HLH patients.

\section{Abbreviations}

AR: Autosomal recessive; CMV: Cytomegalovirus; CT: Computed tomography; EBV: Epstein-Barr virus; FVII: Factor VIl; HLH: Hemophagocytic lymphohistiocytosis; NGS: Next generation sequencing; PBMC: Peripheral blood mononuclear cell; PT: Prothrombin time

\section{Acknowledgements}

We thank the patients and their family members.

\section{Funding}

This work was partially supported by the National Natural Science Foundation of China (No. 81500925), and Health and Family Planning Commission of Hubei Province 2018 Joint Fund (No. WJ2018H0113).

\section{Availability of data and materials}

All data generated or analyzed during this study are included in this published article.

\section{Authors' contributions}

WC and YL conceived the experiments. XW performed genetic test and genetic counselling for congenital factor VII deficiency. XW wrote the manuscript. NT performed coagulation tests and NK cell activity assay. DL cared the patient and provided patient samples.

\section{Ethics approval and consent to participate}

This study was approved guidelines by the Ethics Committee of Tongji Hospital, Tongji Medical College, Huazhong University of Science and Technology. Written informed consent were obtained from all family members.

\section{Consent for publication}

Written informed consent for publication of medical data and genetic data were obtained from all family members.

\section{Competing interests}

The authors declare that they have no competing interests.

\section{Publisher's Note}

Springer Nature remains neutral with regard to jurisdictional claims in published maps and institutional affiliations.

Received: 24 May 2018 Accepted: 27 August 2018

Published online: 12 September 2018

\section{References}

1. Creput C, Galicier L, Buyse S, Azoulay E. Understanding organ dysfunction in hemophagocytic lymphohistiocytosis. Intensive Care Med. 2008:34(7):1177-87.

2. Sepulveda FE, de Saint Basile G. Hemophagocytic syndrome: primary forms and predisposing conditions. Curr Opin Immunol. 2017;49:20-6.

3. Castelli AA, Rosenthal DG, Bender Ignacio R, Chu HY. Hemophagocytic Lymphohistiocytosis secondary to human immunodeficiency virusassociated histoplasmosis. Open forum infectious diseases. 2015;2(4):ofv140.

4. Ishii E, Ohga S, Imashuku S, Yasukawa M, Tsuda H, Miura I, Yamamoto K, Horiuchi H, Takada K, Ohshima K, et al. Nationwide survey of hemophagocytic lymphohistiocytosis in Japan. Int J Hematol. 2007;86(1):58-65.

5. Xu XJ, Wang HS, Ju XL, Xiao PF, Xiao Y, Xue HM, Shi HY, Gao YJ, Jia GC, Li $X R$, et al. Clinical presentation and outcome of pediatric patients with hemophagocytic lymphohistiocytosis in China: a retrospective multicenter study. Pediatr Blood Cancer. 2017;64(4). https://doi.org/10.1002/pbc.26264.

6. Mohan N, Karkra S, Jolly AS, Vohra V, Mohanka R, Rastogi A, Soin AS. First living-related liver transplant to cure factor VII deficiency. Pediatr Transplant. 2015;19(6):E135-8.

7. Giansily-Blaizot M, Verdier R, Biron-Adreani C, Schved JF, Bertrand MA, Borg JY, Le cam-Duchez V, Briquel ME, Chambost H, Pouymayou K, et al. Analysis of biological phenotypes from 42 patients with inherited factor VII deficiency: can biological tests predict the bleeding risk? Haematologica. 2004;89(6):704-9.

8. Hou H, Zhou Y, Yu J, Mao L, Bosco MJ, Wang J, Lu Y, Mao L, Wu X, Wang F, et al. Establishment of the reference intervals of lymphocyte function in healthy adults based on IFN-gamma secretion assay upon Phorbol-12Myristate-13-acetate/lonomycin stimulation. Front Immunol. 2018;9:172.

9. Kumar M, Kothari N, Gupta BD, Gupta N. Hemophagocytic lymphohistiocytosis presenting with acute liver failure and central nervous system involvement in early infancy. Indian J Pathol Microbiol. 2018;61(2):281-3.

10. Henter II, Horne A, Arico M, Egeler RM, Filipovich AH, Imashuku S, Ladisch S, McClain K, Webb D, Winiarski J, et al. HLH-2004: diagnostic and therapeutic guidelines for hemophagocytic lymphohistiocytosis. Pediatr Blood Cancer. 2007;48(2):124-31.

11. Wang X, Lyu Y, Shen N, Hu Q, Lu Y. FVIII p.Arg1800His mutation is associated with mild/moderate hemophilia $A$ in Chinese population. Int J Lab Hematol. 2018. https://doi.org/10.1111/ijlh.12851. [Epub ahead of print].

12. Song Y, Pei RJ, Wang YN, Zhang J, Wang Z. Central nervous system involvement in Hemophagocytic Lymphohistiocytosis in adults: a retrospective analysis of 96 patients in a single center. Chin Med J. 2018;131(7):776-83.

13. Chandrakasan S, Filipovich AH. Hemophagocytic lymphohistiocytosis: advances in pathophysiology, diagnosis, and treatment. J Pediatr. 2013;163(5):1253-9. 
14. Hoffman M, Monroe DM. Coagulation 2006: a modern view of hemostasis. Hematol Oncol Clin North Am. 2007;21(1):1-11.

15. Sevenet PO, Kaczor DA, Depasse F. Factor VII deficiency: from basics to clinical laboratory diagnosis and patient management. Clin Appl Thromb Hemost. 2017;23(7):703-10.

16. Peyvandi F, Jenkins PV, Mannucci PM, Billio A, Zeinali S, Perkins SJ, Perry DJ. Molecular characterisation and three-dimensional structural analysis of mutations in 21 unrelated families with inherited factor VII deficiency. Thromb Haemost. 2000;84(2):250-7.

17. Katsumi A, Matsushita T, Yamazaki T, Sugiura I, Kojima T, Saito H. Severe factor VII deficiency caused by a novel mutation His348 to Gln in the catalytic domain. Thromb Haemost. 2000;83(2):239-43.

18. Han AR, Lee HR, Park BB, Hwang IG, Park S, Lee SC, Kim K, Lim HY, Ko YH, Kim SH, et al. Lymphoma-associated hemophagocytic syndrome: clinical features and treatment outcome. Ann Hematol. 2007:86(7):493-8.

19. Arca M, Fardet L, Galicier L, Riviere S, Marzac C, Aumont C, Lambotte O, Coppo P. Prognostic factors of early death in a cohort of 162 adult haemophagocytic syndrome: impact of triggering disease and early treatment with etoposide. Br J Haematol. 2015;168(1):63-8.

20. Buyse S, Teixeira L, Galicier L, Mariotte E, Lemiale V, Seguin A, Bertheau P, Canet $\mathrm{E}$, de Labarthe A, Darmon M, et al. Critical care management of patients with hemophagocytic lymphohistiocytosis. Intensive Care Med. 2010;36(10):1695-702.

21. Celkan T, Alhaj S, Civilibal M, Elicevik M. Control of bleeding associated with hemophagocytic syndrome in children: an audit of the clinical use of recombinant activated factor VII. Pediatr Hematol Oncol. 2007;24(2):117-21.

22. Aitken MG. Recombinant factor Vlla. Emerg Med Australas. 2004;16(5-6): 446-55.

23. Zhuang JL, Jiang QW, X Y Y, Wang SJ. Recombinant activated factor VII in hemophagocytic lymphohistiocytosis with disseminated intravascular coagulation. Chin Med J. 2011;124(19):3189-91.

Ready to submit your research? Choose BMC and benefit from:

- fast, convenient online submission

- thorough peer review by experienced researchers in your field

- rapid publication on acceptance

- support for research data, including large and complex data types

- gold Open Access which fosters wider collaboration and increased citations

- maximum visibility for your research: over $100 \mathrm{M}$ website views per year

At $\mathrm{BMC}$, research is always in progress.

Learn more biomedcentral.com/submissions 